\title{
Maternal death after oocyte donation at high maternal age: case
} report

\author{
Joke M Schutte*1, Nico WE Schuitemaker ${ }^{2}$, Eric AP Steegers³, Jos van \\ Roosmalen ${ }^{4,5}$ for the Dutch Maternal Mortality Committee
}

Address: ${ }^{1}$ University Medical Center Groningen, Groningen, The Netherlands, ${ }^{2}$ Diaconessen Hospital Utrecht, Utrecht, The Netherlands, ${ }^{3}$ Erasmus MC, University Medical Center Rotterdam, Rotterdam, The Netherlands, ${ }^{4}$ Leiden University Medical Center, Leiden, The Netherlands and ${ }^{5} \mathrm{VU}$ University Medical Center Amsterdam, Amsterdam, The Netherlands

Email: Joke M Schutte* - jokeschutte@og.umcg.nl; Nico WE Schuitemaker - n.schuitemaker@planet.nl;

Eric AP Steegers - e.a.p.steegers@erasmusmc.nl; Jos van Roosmalen - j.j.m.van_roosmalen@lumc.nl

* Corresponding author

Published: 30 December 2008

Reproductive Health 2008, 5:12 doi:10.1/86/1742-4755-5-12
Received: 13 November 2008

Accepted: 30 December 2008

This article is available from: http://www.reproductive-health-journal.com/content/5/I/12

(c) 2008 Schutte et al; licensee BioMed Central Ltd.

This is an Open Access article distributed under the terms of the Creative Commons Attribution License (http://creativecommons.org/licenses/by/2.0), which permits unrestricted use, distribution, and reproduction in any medium, provided the original work is properly cited.

\begin{abstract}
Background: The percentage of women giving birth after the age of 35 increased in many western countries. The number of women remaining childless also increased, mostly due to aging oocytes. The method of oocyte donation offers the possibility for infertile older women to become pregnant. Gestation after oocyte-donation-IVF, however, is not without risks for the mother, especially at advanced age.
\end{abstract}

Case presentation: An infertile woman went abroad for oocyte-donation-IVF, since this treatment is not offered in The Netherlands after the age of 45 . The first oocyte donation treatment resulted in multiple gestation, but was ended by induced abortion: the woman could not cope with the idea of being pregnant with twins. During the second pregnancy after oocyte donation, at the age of 50 , she was mentally more stable. The pregnancy, again a multiple gestation, was uneventful until delivery. Immediately after delivery the woman had hypertension with nausea and vomiting. A few hours later she had an eclamptic fit. HELLP-syndrome was diagnosed. She died due to cerebral haemorrhage.

Conclusion: In The Netherlands, the age limit for women receiving donor oocytes is 45 years and commercial oocyte donation is forbidden by law. In other countries there is no age limit, the reason why some women are going abroad to receive the treatment of their choice.

Advanced age, IVF and twin pregnancy are all risk factors for pre-eclampsia, the leading cause of maternal death in The Netherlands.

Patient autonomy is an important ethical principle, but doctors are also bound to the principle of 'not doing harm', and do have the right to refuse medical treatment such as IVF-treatment. The discussion whether women above $\mathbf{5 0}$ should have children is still not closed. If the decision is made to offer this treatment to a woman at advanced age, the doctor should counsel her intensively about the risks before treatment is started. 


\section{Background}

In the Netherlands the proportion of women giving birth after the age of 35 increased from $5.2 \%$ in 1980 to $20 \%$ in 2003 [1]. This has also been reported in other countries [2].

The number of women remaining childless also increased, mostly due to aging oocytes [3]. The method of oocyte donation from younger women and in vitro fertilization (IVF), offers the possibility for infertile older women to become pregnant. However, this is not without risks for the mother [4].

In The Netherlands, the age limit for women receiving donor oocytes is 45 years [5]. In many other countries the maximum age is higher and sometimes even without limits. Also, in The Netherlands, commercial oocyte donation is forbidden by law (so called embryo law, implemented in 2002), therefore, some women are going abroad to receive the treatment of their choice.

In this short communication we present a case of maternal death, illustrating that the application of new technologies of assisted reproduction in high income countries creates a new group of women at risk of maternal death.

\section{Case presentation}

The woman got pregnant for the first time at the age of 36 but had a miscarriage twice. When she was 38 years old, she had two induced abortions. At the age of 41 and 43 years, she got pregnant after ovulation induction, and gave birth to a healthy girl and boy respectively. After this, she suffered from secondary subfertility, but ovulation induction did not result in pregnancy. At the age of 46, after oocyte donation embryotransfer was performed abroad, resulting in a twin pregnancy. However, the woman could not live with the idea of carrying twins. She first opted for termination of pregnancy, but then agreed with selective foeticide in the same clinic. She could still not cope with the pregnancy and opted for abortion of the second twin in the second trimester.

At the age of 49 she again had oocyte donation and IVF in another clinic abroad, resulting in a twin pregnancy. She now seemed to be mentally more stable. Antenatal visits were at a Dutch clinic, and the pregnancy developed uneventful. At a gestational age of 37 weeks her blood pressure had risen from $110 / 60$ to $125 / 80 \mathrm{mmHg}$. At 38 weeks labour was induced for elective reasons and the woman delivered a healthy boy and girl, at the age of 50. Shortly after delivery her blood pressure had risen to $170 / 100$ $\mathrm{mmHg}$. She complained of nausea and vomiting. No diagnostic tests, however, were performed and no antihypertensive or anticonvulsant therapy was initiated. Nine hours later she was found unconscious in bed with a tongue bite. Magnesium sulfate was initiated, but she had two more convulsions. Blood results showed signs of HELLP-syndrome. Following the eclamptic fit she was somnolent and disoriented, with a blood pressure of 140/ $85 \mathrm{mmHg}$. After 24 hours the CT-scan showed occipital haemorrhage and cerebral oedema. The woman was transferred to the Intensive Care Unit. After a few hours the Glasgow Coma Scale deteriorated and a midline shift was visible on the CT scan. Treatment was stopped because of brain death. Her husband was left behind with four children.

\section{Discussion}

This woman died from eclampsia, after she had a multiple pregnancy at advanced age after oocyte donation IVF. She insisted to have this treatment and being denied IVF in her own country, The Netherlands, she had it performed abroad. The woman had hypertension and pre-eclamptic complaints, but was not managed with antihypertensive medication or magnesium sulphate.

We feel that even the first oocyte donation for this woman could be criticised, but are astonished that doctors did institute such rigorous treatment for the second time, at the age of 49, after the first pregnancy resulting from oocyte donation was chosen to be terminated. The availability of advanced reproductive technology, especially for the wealthier women in society, may create a new, unnecessary group at risk for severe maternal morbidity and mortality in high income countries. Women should be counselled intensively about the risks involved.

IVF, twin pregnancy and advanced age are all risk factors for pre-eclampsia, one of the five major causes of maternal death worldwide, and the leading cause of maternal mortality in The Netherlands.

IVF-pregnancies are associated with more obstetric complications than naturally conceived pregnancies [6]. Källén et al found higher risks of pre-eclampsia (OR 1.63; 95\% CI 1.53-1.74), placental abruption (OR 2.17; 95\% CI 1.74-2.72) and postpartum haemorrhage (OR 1.4; 9\% CI 1.38-1.50) in women being pregnant after IVF-treatment [7]. Venn et al reported an increased risk of maternal mortality in IVF pregnancies: 25.7 per 100.000 pregnancies compared to 10.9 in non-IVF pregnancies [8].

Whether oocyte donation adds an additional risk to the higher risks of obstetric complications in IVF-pregnancies remains controversial, but most studies indicate an additional risk. Söderström-Anttila et al compared obstetric outcome of pregnancy after oocyte donation with pregnancies after standard IVF. In singleton pregnancies they observed 29\% (12/41) pregnancy-induced hypertension in the first group versus $12 \%(8 / 68)$ in the other group $(P$ 
$<0.05)$. Also, the caesarean section rate was higher: $57 \%$ $(29 / 51)$ in the group with oocyte donation versus $37 \%$ $(36 / 97)$ in the standard IVF group [9].

Henne et al found an increased risk of preterm labour, pre-eclampsia and caesarean delivery (after controlling for age and multiple gestations) in recipients of donor oocytes versus women of advanced age with autologous oocytes [10]. Wiggins et al found 26\% (6/23) pregnancyinduced hypertension in the group with donor egg IVF as compared to $8 \%(1 / 12)$ in the group with standard IVF. For nulliparous women this difference was even more significant with $37 \%(13 / 35)$ in the donor egg IVF group and $8 \%(3 / 37)$ in the group with standard IVF (OR 7.1; 95\% CI 1.4-36.7) [11]. Sauer et al reported in their cohort study in $37.8 \%$ (28/74) of pregnancies after oocyte donation obstetrical complications [12]. This was also seen in the cohort of Abdalla, with a high risk of pregnancy induced hypertension and postpartum haemorrhage [13].

Krieg et al compared 71 donor oocyte pregnancies with 108 IVF pregnancies using autologous oocytes at advanced maternal age. They found no differences in incidence of hypertensive disorders, gestational diabetes or mode of delivery after controlling for multifetal gestation, gestational age at delivery and maternal age [14].

Women being pregnant at advanced age have an increased risk for pre-eclampsia and gestational diabetes [15]. Advanced age is also an independent risk factor for caesarean delivery (OR 2.3, 95\% CI 1.1-4.8) [16]. Paulson et al reported an incidence of pre-eclampsia of $25 \%(10 / 40)$, being $60 \%(6 / 10)$ in women older than 55 years. The incidence of gestational diabetes was $17.5 \%(7 / 40)$, with an incidence of $40 \%$ in women older than 55 years $(4 / 10)$ [17]. Doctors offering IVF procedures should be aware of the risks named above.

Patient autonomy is an important ethical principle in management, but we feel that there are limits to this. Doctors are also bound to the principle of 'not doing harm' and this principle was at stake in our case [18]. The discussion whether women over the age of 50 should have children is still not closed [2,3]. Landau even reports an increase, rather than a decrease, of human suffering due to the promise of post-menopausal pregnancy with unlimited fertility [19]. Doctors do have the right to refuse to give medical treatment such as IVF-treatment. If it is decided to offer this treatment to a woman at advanced age, she should be counseled intensively about the risks before such treatment is started.

\section{Conclusion}

The discussion whether women at advanced maternal age should become pregnant is still not closed. Doctors, how- ever, have the right to refuse to perform such treatment. Pregnancies at advanced maternal age after oocyte IVFtreatment have increased risks of obstetrical complications. We should be aware of these risks and counsel patients accordingly.

\section{Consent}

Written informed consent was obtained from the husband of the patient for publication of this case report and any accompanying images. A copy of the written consent is available for review by the Editor-in-Chief of this journal.

\section{Competing interests}

The authors declare that they have no competing interests.

\section{Authors' contributions}

All authors have made substantive intellectual contributions to this study. We all contributed to the conception of the article and to the acquisition and analysis of the case. All authors read and approved the final manuscript.

\section{References}

I. Statistics Netherlands. Voorburg 2004

2. Cunningham FG, Leveno KJ: Childbearing among Older Women-The message is Cautiously Optimistic. N Engl J Med 1995, 333:1002-4.

3. Speroff L: The effect of aging on fertility. Curr Opin Obstet Gynecol 1994, 6: II5-20.

4. Duckitt K, Harrington D: Risk factors for pre-eclampsia at antenatal booking: systematic review of controlled studies. $B M$ J 2005, 330:565-7.

5. Guideline 'High technology donorship'. The Netherlands Society of Obstetrics and Gynaecology 1998.

6. Allen VM, Wilson RD, Cheung A: Pregnancy outcomes after assisted reproductive technology. J Obstet Gynaecol Can 2006, 28:220-50.

7. Källén $B$, Finnstrom $O$, Nygren KG, Otterblad Olausson P, Wennerholm UB: In vitro fertilisation in Sweden: obstetric characteristics, maternal morbidity and mortality. BJOG 2005, I I 2:1529-1535.

8. Venn A, Hemminski E, Watson L, et al:: Mortality in cohort of IVF patients. Hum Reprod 200I, 16:269I-6.

9. Söderström-Anttila V, Foudila TA, Hovatta O: Obstetric and perinatal outcome after oocyte donation: comparison with invitro fertilization pregnancies. Hum Reprod 1998, 13:483-90.

10. Henne MB, Zhang M, Paroski S, Kelshikar B, Westphal LM: Comparison of obstetric outcomes in recipients of donor oocytes vs. women of advanced maternal age with autologous oocytes. J Reprod Med 2007, 52:585-90.

II. Wiggins DA, Main E: Outcomes of pregnancies achieved by donor egg in vitro fertilization - a comparison with standard in vitro fertilization pregnancies. AJOG 2005, 192:2002-8.

12. Sauer MV, Paulson RJ, Lobo RA: Oocyte donation to women of advanced reproductive age: pregnancy results and obstetrical outcomes in patients $\mathbf{4 5}$ years and older. Hum Reprod 1996, I I:2540-3.

13. Abdalla HI, Billett A, Kan AKS, et al.: Obstetric outcome in $\mathbf{2 3 2}$ ovum donation pregnancies. BJOG 1998, 105:332-7.

14. Krieg SA, Henne MB, Westphal LM: Obstetric outcomes in donor oocyte pregnancies compared with advanced maternal age in in vitro fertilization pregnancies. Fertil Steril 2008, 90:65-70.

15. Jacobsson B, Ladfors L, Milsom I: Advanced maternal age and adverse perinatal outcome. Obstet Gynecol 2004, 104:727-33.

16. Peipert JF, Bracken MB: Maternal age: an independent risk factor for cesarean delivery. Obstet Gynecol 1993, 81:200-5. 
17. Paulson RJ, Boostanfar R, Saadat P: Pregnancy in the sixt decade of life. Obstetric outcomes in women of advanced reproductive age. JAMA 2002, 288:2320-3.

18. American College of Obstetricians and Gynecologists Committee Opinion: Surgery and patient choice: The ethics of decision making. Obstet Gynecol 2003, 102: I 101-1 106.

19. Landau $R$ : The promise of post-menopausal pregnancy (PMP). Soc Work Health Care 2004, 40:53-69.

Publish with Bio Med Central and every scientist can read your work free of charge

"BioMed Central will be the most significant development for disseminating the results of biomedical research in our lifetime. " Sir Paul Nurse, Cancer Research UK

Your research papers will be:

- available free of charge to the entire biomedical community

- peer reviewed and published immediately upon acceptance

- cited in PubMed and archived on PubMed Central

- yours - you keep the copyright

Submit your manuscript here:

http://www.biomedcentral.com/info/publishing_adv.asp 